\title{
Discovery of a potent small molecule SIRT1/2 inhibitor with anticancer effects
}

\author{
GILDON CHOI ${ }^{1 *}$, JONGKOOK LEE ${ }^{2 *}$, JEONG YEON JI ${ }^{3}$, JIMIN WOO $^{1}$, NAM SOOK KANG ${ }^{4}$, \\ SUNG YUN CHO ${ }^{1}$, HYOUNG RAE KIM $^{1}$, JAE DU HA ${ }^{1}$ and SUN-YOUNG HAN ${ }^{3}$
}

\author{
${ }^{1}$ Korea Research Institute of Chemical Technology and University of Science and Technology (UST), Daejeon; \\ ${ }^{2}$ College of Pharmacy, Kangwon National University, Chuncheon; ${ }^{3}$ College of Pharmacy and Research Institute \\ of Pharmaceutical Sciences, Gyeongsang National University, Jinju, Gyeongnam; ${ }^{4}$ Graduate School of \\ New Drug Discovery and Development, Chungnam National University, Daejeon, Republic of Korea
}

Received May 21, 2013; Accepted July 2, 2013

DOI: 10.3892/ijo.2013.2035

\begin{abstract}
SIRT1 and SIRT2 are deacetylase enzymes that belong to the sirtuin family and are involved in tumorigenesis. In our screen for small molecules inhibiting SIRT1/2 toxoflavin was identified. Toxoflavin potently inhibited SIRT1 activity in in vitro deacetylase assay using purified SIRT1 protein. SIRT2 activity was also inhibited by toxoflavin less potently than SIRT1 in deacetylase assay in vitro. Toxoflavin exhibited growth inhibition of various cancer cell lines including A549 lung cancer cells with a $\mathrm{GI}_{50}$ of $48 \mathrm{nM}$. Toxoflavin treatment in A549 cells increased the acetylated form of p53, which is a substrate of SIRT1. The acetylation levels of $\alpha$-tubulin, a SIRT2 substrate, were also increased by toxoflavin treatment dose-dependently. Several toxoflavin derivatives were synthesized to determine the preliminary structure-activity relationship of toxoflavin. Some of the toxoflavin derivatives showed highly selective inhibition against SIRT1. In conclusion, this study presented toxoflavin as a potent SIRT1/2 inhibitor with anticancer activity.
\end{abstract}

\section{Introduction}

SIRT1 and SIRT2 are enzymes that belong to the sirtuin family, also known as class III histone deacetylases. The sirtuin prototype was found in yeast as a silent information regulator 2 (Sir2). Seven mammalian sirtuins (SIRT1-SIRT7) have been reported so far and they have roles in genome stability, stress response, lifespan and tumorigenesis (1).

SIRT1, closest to yeast Sir2 in terms of sequence, mediates heterochromatin formation through histone deacetylation.

Correspondence to: Dr Sun-Young Han, College of Pharmacy, Gyeongsang National University, 501 Jinju-daero, Jinju 660-701, Republic of Korea

E-mail: syhan@gnu.ac.kr

*Contributed equally

Key words: SIRT1, SIRT2, toxoflavin, anticancer agent
Deacetylation of specific lysine residues in histone H1, H3 and H4 by SIRT1 plays an important role in chromatin regulation and epigenetic modification. SIRT1 also has substrates which are non-histone proteins such as p53, FOXO and Rb. Through deacetylation of these substrates, SIRT1 is linked to a variety of physiological functions (2). SIRT2 is mainly cytoplasmic and has been characterized for diverse cellular functions. At first, SIRT2 was reported as a deacetylase for $\alpha$-tubulin, regulating the microtubule network (3). Furthermore, later, SIRT2 was also found to deacetylate histone $\mathrm{H} 4$ during mitosis, implicating its role as a mitotic checkpoint protein (4).

SIRT1 and SIRT2 seem to be involved in tumorigenesis. Overexpression of SIRT1 was observed in several tumors including leukemia, lymphoma, skin cancer, prostate cancer, hepatocellular carcinoma, gastric carcinoma and colorectal cancer (5). However, the function of SIRT1 in tumorigenesis seems to be context-dependent, because there are contradictory reports about whether SIRT1 acts as a tumor suppressor or not. SIRT2 is involved in the regulation of cancer cell motility with its tubulin deacetylation function. Overexpression of SIRT2 increased cancer cell motility and decreased sensitivity to paclitaxel treatment, a microtubule inhibiting anticancer drug (6). In addition, SIRT2 inhibition potentiated the effect of paclitaxel in endothelial and tumor cells.

An anticancer effect by SIRT1/2 small molecule inhibitors supports the role of SIRTs as tumor promoters. Several small molecules have been discovered and proposed for cancer therapy (2). The following are reported as sirtuin inhibitors: EX-527 (7), splitomicin (8), sirtinol (9), cambinol (10), AGK2 (11), suramin (12), tenovins (13), salermide (14), JGB1741 (15), UVI5008 (16) and inauhzin (17). Out of these compounds, only four compounds (tenovins, cambinol, UVI5008 and inauhzin) exhibited in vivo antitumor effects in mouse models. The results from sirtuin inhibitors reveal therapeutic potential for anticancer drug development with the mechanism of SIRT inhibition.

In the search for small molecules inhibiting SIRT1/2, toxoflavin, also known as xanthothricin, was identified using biochemical enzymatic assay. Toxoflavin was originally known as a toxin produced from bacteria with antibiotic function (18). The SIRT1/2 inhibitory action of toxoflavin was evaluated 
and cytotoxic activity against cancer cells was investigated as well. With the characterization of toxoflavin, novel and potent SIRT1/2 inhibitors with antitumor property were presented in this study.

\section{Materials and methods}

In vitro SIRT1 assay. SIRT1 activity measurements were carried out in a 384-well black plate (7). The enzymatic reaction was performed at room temperature in a buffer solution containing $50 \mathrm{mM}$ Tris- $\mathrm{HCl} \mathrm{pH} 7.5,100 \mathrm{mM} \mathrm{NaCl}, 7.5 \mathrm{mM}$ $\mathrm{MgCl}_{2}, 3 \mathrm{mM} \mathrm{KCl}, 0.01 \%$ Tween-20, 0.1\% BSA, $1 \mathrm{mM}$ DTT, $125 \mathrm{nM}$ biotinylated peptide with an acetylated FLAG sequence (Cisbio, France), $130 \mu \mathrm{M}$ NAD and the appropriate amount of SIRT1 enzyme (Biomol, Farmingdale, NY, USA). Compounds were serially diluted ranging from 0.003 to $10 \mu \mathrm{M}$ for SIRT1 inhibition experiments. All reaction components except NAD were added to the wells first and the reaction was started by adding NAD to the assay mixture. After incubation for $3 \mathrm{~h}$, the reaction was stopped by adding the solution containing europium-cryptate conjugated anti-FLAG antibody, streptavidin-XL665 (Cisbio) and SIRT1 inhibitor nicotinamide. The plate was incubated further at room temperature for $1 \mathrm{~h}$. Timeresolved fluorescence resonance energy transfer (TR-FRET) between europium cryptate (donor) and XL665 (acceptor) was measured in EnVision multilabel reader (Perkin-Elmer, Waltham, MA, USA). The signal ratio at $665 / 615 \mathrm{~nm}$ was used in all data analyses.

In vitro SIRT2 assay. SIRT2 activity measurements were performed in a 96-well plate format. The substrate mixture containing biotin labeled histone $\mathrm{H} 4$ peptide with an acetylated lysine 4 (Anaspec, Fremont, CA, USA) and NAD was prepared in a buffer solution containing $50 \mathrm{mM}$ Tris- $\mathrm{HCl}$ (pH 8.0), $100 \mathrm{mM} \mathrm{NaCl}, 2 \mathrm{mM} \mathrm{MgCl}_{2}, 0.1 \%$ BSA and $1 \mathrm{mM}$ DTT. The substrate mixture and the appropriately diluted toxoflavin solution were distributed in a 96 -well polystyrene plate for inhibition experiments. The enzyme reaction was started by adding SIRT2 enzyme (SignalChem, Canada) and processed at $37^{\circ} \mathrm{C}$ for $1 \mathrm{~h}$ with gentle shaking. Nicotinamide was added to the wells to stop the reaction.

The resulting mixtures were transferred to the wells of streptavidin-coated microplates (Pierce) and incubated for $1 \mathrm{~h}$. After washing three times with the phosphate-buffered saline containing $0.05 \%$ Tween-20 (PBST), the plates were incubated with anti-acetyl-histone H4 (Lys16) antibody (Abcam 07-329, Cambridge, MA) for $1 \mathrm{~h}$. After removing the primary antibody and washing the plates with PBST, horseradish peroxidase (HRP)-conjugated secondary antibody was added and incubated for $30 \mathrm{~min}$. After incubation, the wells were emptied and washed with PBST three times. After the final wash, HRP substrates (Applied Biosystems, Carlsbad, CA, USA) were added to the wells and incubated at room temperature for $1 \mathrm{~h}$ without shaking. The extent of the reaction was determined by measuring the luminescence signals from the wells.

Synthesis of toxoflavin (1) and its derivatives (2-7). Toxoflavin (1) and its derivatives (2-7) were synthesized according to literature procedures (19-21).
Cell culture and cytotoxicity assay. Cell lines were cultured under a humidified $5 \% \mathrm{CO}_{2}$ incubator at $37^{\circ} \mathrm{C}$ in DMEM (A549) or RPMI (DU-145, SK-OV-3, MCF-7, MKN-45, PANC-1, HEL 92.1.7 and MV-4;11) supplemented with $10 \%$ fetal bovine serum (FBS). Cells were plated in 96-well plate $(2,000$ cells/ well) and serial dilutions of toxoflavin compound were added. At the end of the incubation period ( $72 \mathrm{~h}$ ), cell viability was measured using tetrazolium-based Ez CyTox cell viability assay kit (Daeil, Korea). Growth inhibition (50\%) $\left(\mathrm{GI}_{50}\right)$ was calculated by a non-linear regression using Prism version 5.01 (Graphpad, La Jolla, CA, USA).

Immunoblot analysis. Samples of cell extracts prepared in SDS lysis buffer (12 mM Tris-Cl, $\mathrm{pH} \mathrm{6.8,5 \%} \mathrm{glycerol,}$ $0.4 \%$ SDS) were resolved by SDS-PAGE and transferred to PVDF membrane. The filters were blocked in Tris-buffered saline $(10 \mathrm{mM}$ Tris- $\mathrm{Cl}, \mathrm{pH} 7.4,140 \mathrm{mM} \mathrm{NaCl})$ containing $0.1 \%$ Tween-20 and 5\% non-fat dry milk and then incubated with blocking solution containing the indicated antibodies for $2 \mathrm{~h}$. The filters were visualized with HRP-coupled secondary antibodies and enhanced chemiluminiscence reagent (Thermo Scientific Pierce, Rockford, IL, USA). The primary antibodies used were SIRT1 (H-300), SIRT2 (H-95), p53 (Pab 1801) (Santa Cruz Biotechnology Inc., Dallas, TX, USA), acetylated p53 (Lys382) (Cell Signaling Technology, Danvers, MA, USA), $\beta$-actin (Sigma, St. Louis, MO, USA). The secondary antibodies were purchased from Jackson ImmunoReserach (West Grove, PA, USA).

Migration assay. For measurement of cell migration, cells were incubated with various concentrations $(0-10 \mu \mathrm{M})$ of toxoflavin for $24 \mathrm{~h}$. Cells $(100,000 /$ well $)$ in DMEM with $0.1 \%$ FBS were plated to the upper chamber of Transwell (Costar 3422, Tweksbur, MA, USA) containing a membrane with pores of $8 \mu \mathrm{m}$. The cells were allowed to migrate for $24 \mathrm{~h}$ into the lower chamber containing DMEM with $10 \%$ FBS. Cells on top of the Transwell were removed by scraping and those on the bottom were stained with $1 \%$ crystal violet solution and photographed.

Flow cytometry. A549 cells were treated with toxoflavin for 24 and $48 \mathrm{~h}$, respectively. Cells were then fixed and stained with propidium iodide (Sigma) and subjected to flow cytometry using Accuri C6 Flow cytometer (BD Biosciences, Billerica, MA, USA). Data were analyzed by CFlow Plus (BD Biosciences).

\section{Results}

Activity of toxoflavin on purified human SIRT1 and SIRT2 protein. In the course of screening for SIRT1/2 inhibitors with anticancer effects, toxoflavin was identified to affect both SIRT1 and SIRT2 in vitro activity. Purified recombinant protein for SIRT1 and SIRT2 were used for measurement of deacetylase activity using TR-FRET and ELISA method, respectively. As shown in Fig. 1A, direct inhibition of SIRT1 and SIRT2 activity by toxoflavin was observed. Toxoflavin inhibited SIRT1 more potently than SIRT2 $\left(\mathrm{IC}_{50} 0.872 \mu \mathrm{M}\right.$ for SIRT1 and $\mathrm{IC}_{50} 14.4 \mu \mathrm{M}$ for SIRT2). Potent small molecule SIRT1 inhibitor EX-527 (7), exhibited similar activity with toxoflavin in SIRT1 inhibition (data not shown). Among SIRT1 

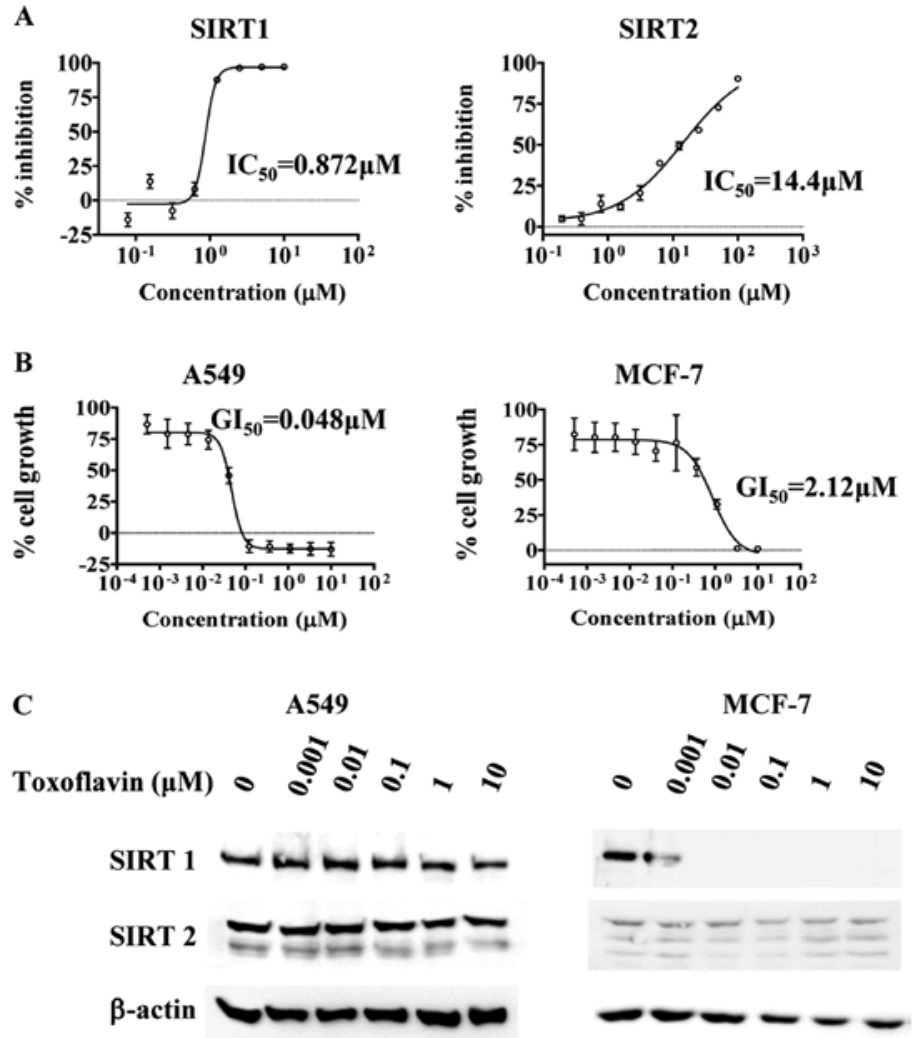

Figure 1. Effects of toxoflavin on in vitro SIRT1/2 activity and cancer cell growth. (A) In vitro SIRT1 (left) and SIRT2 activity (right) were measured as described in Materials and methods. Indicated concentrations of toxoflavin were added to purified SIRT1 or SIRT2 enzyme and deacetylase activity was measured. (B) Growth inhibition of A549 (left) and MCF-7 cells (right) were measured using tetrazolium-based cell viability assay. Indicated concentrations of toxoflavin were applied for $72 \mathrm{~h}$. Cell growth (\%) was calculated using $0.5 \%$ DMSO treatment as a negative control. $\mathrm{IC}_{50}$ and $\mathrm{GI}_{50}$ were calculated by a non-linear regression. Data are mean \pm SEM of three independent experiments. (C) Expression level of SIRT1 and SIRT2 are shown by western blotting with the indicated concentration of toxoflavin treatment for $8 \mathrm{~h}$

inhibitors reported, EX-527 is one of the compounds with highest inhibitory activity in in vitro recombinant enzyme assay system (22). This great potency of toxoflavin against the SIRT1 enzyme led us to further characterize toxoflavin's anticancer effects with regard to SIRT1/2 inhibition.

Growth inhibition of various tumor cell lines by toxoflavin treatment. Various cancer cell lines were treated with toxoflavin, in order to investigate the effect of toxoflavin on the growth of cancer cells (Table I). Toxoflavin inhibited growth of A549 (lung cancer), MCF-7 (breast cancer), SK-OV-3 (ovarian cancer), DU-145 (prostate cancer), MKN-45 (gastric cancer), PANC-1 (pancreatic cancer), U87MG (CNS cancer) and HEL 91.1.7 (leukemia) and MV-4;11 (leukemia) cells. Non-small cell lung cancer cell line A549 cell growth was affected by toxoflavin with $\mathrm{GI}_{50}$ of a $48 \mathrm{nM}$ and breast cancer cell line MCF-7 cell growth was also inhibited by toxoflavin (Fig. 1B). However, the $\mathrm{GI}_{50}$ for MCF-7 is $2.2 \mu \mathrm{M}$, which is 45-fold difference with $\mathrm{A} 549 \mathrm{GI}_{50}$, meaning toxoflavin is more sensitive in A549 cells than MCF-7 cells. The expression of SIRT1 and SIRT2 proteins in A549 and MCF-7 cells in the presence and absence of toxoflavin is shown in Fig. 1C. In A549 cells, SIRT1 and SIRT2 proteins are expressed and do not change with the treatment of toxoflavin. However, SIRT1 expression in MCF-7 cells is decreased with toxoflavin treatment dose-dependently. The expression level of SIRT2 in MCF-7 cells is lower than that of A549 cells.
Table I. Growth inhibition of various tumor cell lines by toxoflavin treatment. ${ }^{\mathrm{a}}$

\begin{tabular}{lc}
\hline Cell line & $\mathrm{GI}_{50}(\mu \mathrm{M})$ \\
\hline U87MG (CNS cancer) & 0.342 \\
SK-OV-3 (ovarian cancer) & 0.145 \\
DU-145 (prostate cancer) & 0.027 \\
MKN-45 (gastric cancer) & 0.091 \\
PANC-1 (pancreatic cancer) & 0.496 \\
HEL 92.1.7 (leukemia) & 1.042 \\
MV-4;11 (leukemia) & 0.593 \\
\hline
\end{tabular}

${ }^{\mathrm{a}}$ Growth inhibition of tumor cell lines was measured using tetrazolium-based cell viability assay. $\mathrm{GI}_{50}$ were calculated by a non-linear regression. Data are mean of three independent experiments.

Effects of toxoflavin on the acetylated form of p53 and $\alpha$-tubulin. After inhibition in vitro SIRT1/2 activity and cancer cell growth by toxoflavin were confirmed, the toxoflavin effect on the substrates of SIRT1 and SIRT2 in cell-based system was examined. In A549 cells, toxoflavin and trichostatin A (TSA) were treated for $6 \mathrm{~h}$ and acetylated $\mathrm{p} 53$ level was measured by western blotting. p53 is deacetylated by SIRT1 $(23,24)$. Acetylated p53 level is increased by toxoflavin through inhibition of SIRT1 
A

$\begin{array}{rcccc}\text { TSA }(\mathrm{nM}) & 0 & 40 & 40 & 40 \\ \text { Toxoflavin }(\mu \mathrm{M}) & 0 & 0 & 1 & 10 \\ \text { Ac-p53 } & & & & \\ \text { B-actin } & - & \end{array}$

B

MCF-7

TSA (nM) $\quad 0 \quad 40 \quad 40 \quad 40$

Toxoflavin $(\mu \mathrm{M}) \quad 0 \quad 0 \quad 1 \quad 10$

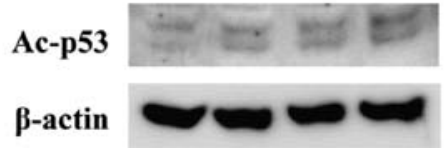

A549

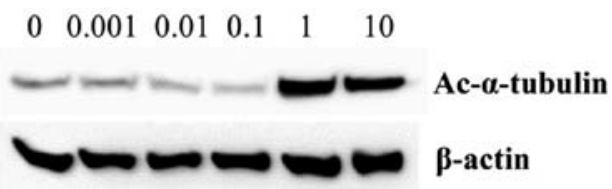

MCF-7

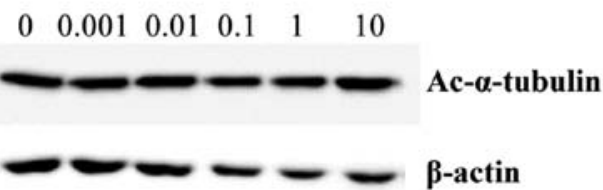

Figure 2. Effects of toxoflavin on the acetylated form of p53 and $\alpha$-tubulin. (A) A549 and MCF-7 cells were treated with indicated concentration of TSA and toxoflavin for $6 \mathrm{~h}$ and subjected to western blotting using acetylated p53 antibody (Ac-p53). (B) A549 and MCF-7 cells were treated with indicated concentration of TSA and toxoflavin for $6 \mathrm{~h}$ and subjected to western blotting using antibody against acetylated $\alpha$-tubulin (Ac- $\alpha$-tubulin).

Table II. Structure-activity relationship of toxoflavin (1) derivatives. ${ }^{a}$<smiles>[R]c1cc2c(=O)n(C)c(=O)nc-2n([R2])n1</smiles>

\begin{tabular}{|c|c|c|c|c|c|c|}
\hline Compound & $\mathrm{R}^{1}$ & $\mathrm{R}^{2}$ & $X$ & $\begin{array}{c}\text { SIRT1 } \\
\mathrm{IC}_{50}(\mu \mathrm{M})\end{array}$ & $\begin{array}{c}\text { SIRT2 } \\
\mathrm{IC}_{50}(\mu \mathrm{M})\end{array}$ & $\begin{array}{l}\text { SK-OV-3 } \\
\mathrm{GI}_{50}(\mu \mathrm{M})\end{array}$ \\
\hline Toxoflavin (1) & $\mathrm{H}$ & $\mathrm{Me}$ & $\mathrm{N}$ & 0.87 & 14.4 & 0.15 \\
\hline 2 & $\mathrm{H}$ & Et & $\mathrm{N}$ & 0.35 & $>100$ & 0.55 \\
\hline 3 & $\mathrm{Bu}$ & $\mathrm{Me}$ & $\mathrm{N}$ & 0.11 & $>100$ & 2.40 \\
\hline 4 & $p$-tolyl & $\mathrm{Me}$ & $\mathrm{N}$ & 0.11 & $>100$ & 2.03 \\
\hline 5 & $p-\mathrm{CF}_{3}$-phenyl & Et & $\mathrm{N}$ & 0.50 & $>100$ & 3.20 \\
\hline 6 & 4-bromothiophen-2-yl & Et & $\mathrm{N}$ & 0.92 & $>100$ & 17.5 \\
\hline 7 & $p$-tolyl & $\mathrm{Me}$ & $\mathrm{C}$ & $>100$ & $>100$ & - \\
\hline
\end{tabular}

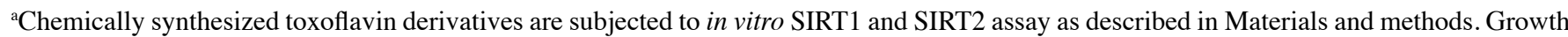
inhibition by the compounds was measured in SK-OV-3 cells.

deacetylase activity in the presence of TSA (Fig. 2). $\alpha$-tubulin is deacetylated by SIRT2 (4). Toxoflavin increased the acetylated form of $\alpha$-tubulin dose-dependently in A549 cells through inhibition of SIRT2. In contrast to A549 cells, the acetylation level of p53 and $\alpha$-tubulin in MCF-7 cells was not changed by toxoflavin treatment (Fig. 2). MCF-7 cells are not sensitive to toxoflavin treatment and this may be related to the difference of cell growth inhibition between A549 and MCF-7 cells.

Effects of toxoflavin on tumor cell death. Toxoflavin induced cell death as shown in the phase contrast image in Fig. 3A. After $72 \mathrm{~h}$ of toxoflavin treatment, complete cell death was observed in 1 and $10 \mu \mathrm{M}$ of toxoflavin treated-A549 cells. Cell death was also observed in flow cytometric results (Fig. 3B). After treatment with toxoflavin for 24 and $48 \mathrm{~h}$, A549 cells were subjected to cell cycle analysis. The sub- $\mathrm{G}_{0} / \mathrm{G}_{1}$ population, indicating dead cells, was increased by toxoflavin treatment dose-dependently. Sub- $\mathrm{G}_{0} /$ $\mathrm{G}_{1}$ population increased from 2.5 (DMSO) to $91 \%(10 \mu \mathrm{M}$ toxoflavin) with 24-h treatment and 1.1 (DMSO) to 98\% (10 $\mu \mathrm{M}$ toxoflavin) with 48 -h treatment. Cell migration was also reduced by toxoflavin. Using the Transwell assay, cell migration was measured in the absence and presence of toxoflavin. Migrated cells were stained with crystal violet. As shown in Fig. 3C, dosedependent inhibition of cell migration was observed.

Structure-activity relationship of toxoflavin derivatives. In order to examine the structure-activity relationship of toxoflavin on the SIRT1/2 inhibitory activity, several derivatives 
A
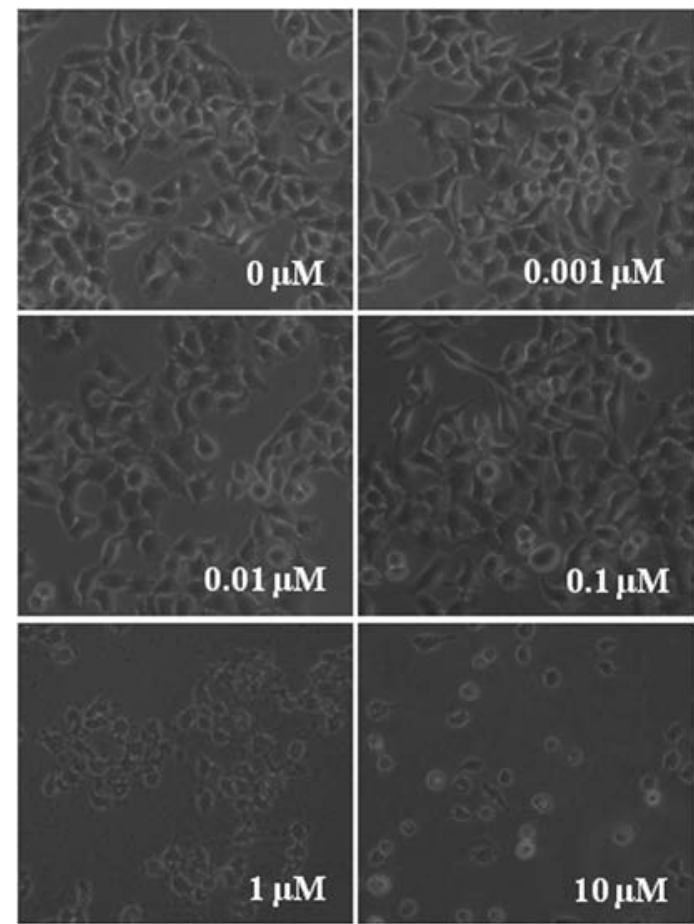

B

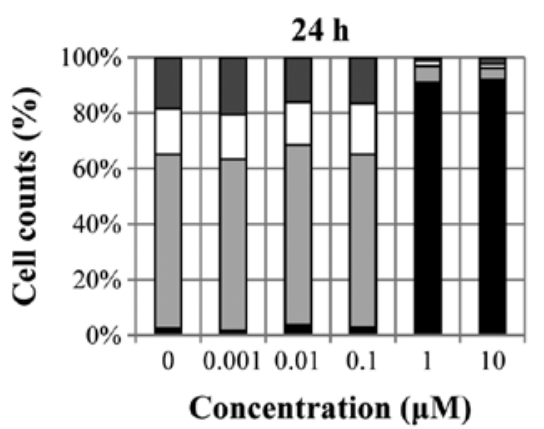

C

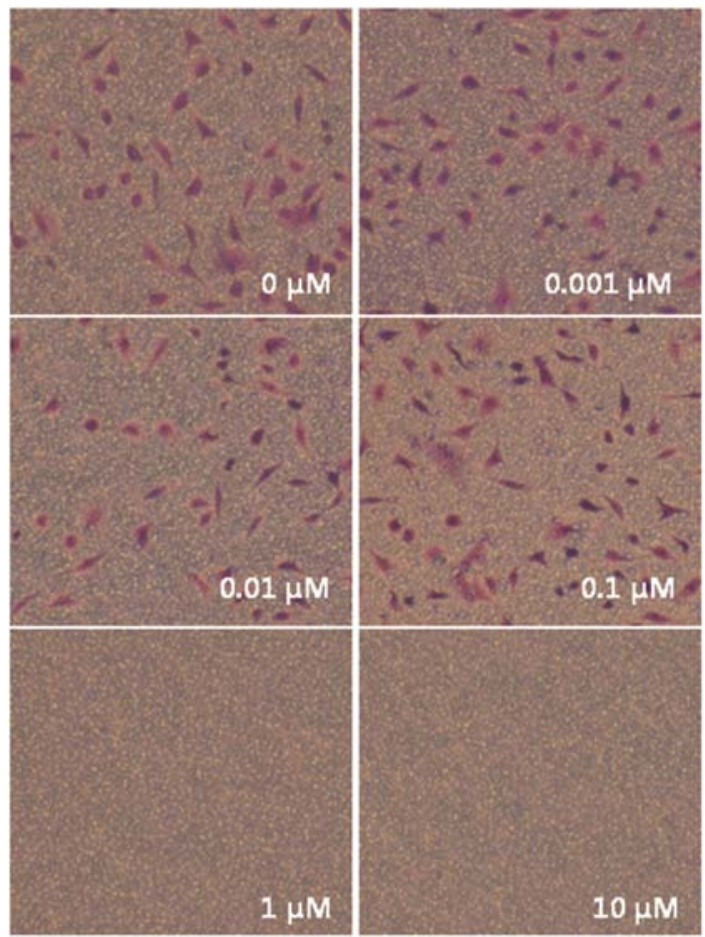

$48 \mathrm{~h}$

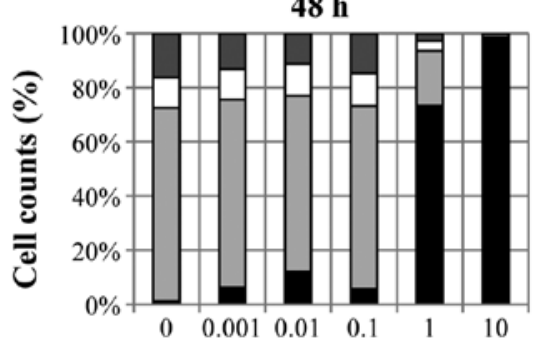

Concentration $(\mu \mathrm{M})$

Figure 3. Effects of toxoflavin on tumor cell death. (A) A549 cells were treated with indicated concentrations of toxoflavin for $72 \mathrm{~h}$ and phase contrast images of cells were taken. (B) A549 cells were treated with toxoflavin for 24 and $48 \mathrm{~h}$, respectively. Cells were stained with prodidium idodide and stained cells were subjected to cell cycle analysis using flow cytometry. (C) Cell migration effect was measured using Transwell assay. In the presence of toxoflavin at the indicated concentration, A549 cells migrated for $24 \mathrm{~h}$ were stained and photographed. Results are representative data of three independent experiments.

A

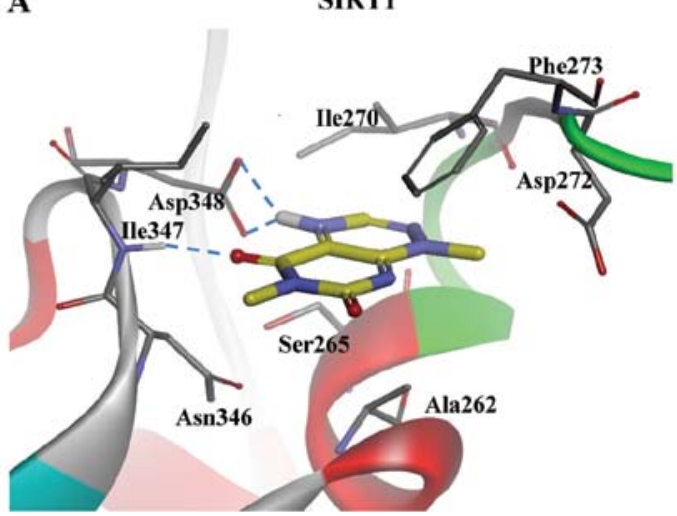

B

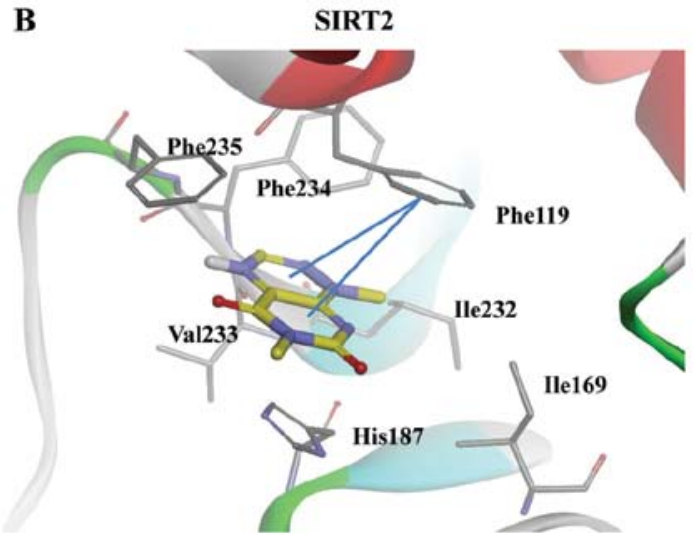

Figure 4. Docking experiment of the SIRT-toxoflavin complex. Interaction of toxoflavin and SIRT1 (A) and SIRT2 (B) protein catalytic core are shown. A docking experiment was performed using the shape-based docking algorithm, LigandFit in Discovery Studio 3.5. The crystal structure of SIRT2 used was taken from the human sirtuin C-pocket (PDB entry; 1J8F). The SIRT1 structure was obtained through the hierarchical protein structure modeling approach.

of toxoflavin were synthesized, as shown in Table II. The inhibitory activity of toxoflavin derivatives against SIRT1 and SIRT2 were measured using in vitro deacetylase activity. Some of the derivatives were more potent than toxoflavin (1) 
against SIRT1. However, all the derivatives were inactive against SIRT2 in an enzymatic assay.

Binding mode of the SIRT-toxoflavin complex. To understand the interaction of the SIRT-toxoflavin complex, a docking experiment was performed using the shape-based docking algorithm, LigandFit in the Discovery Studio 3.5 (25). The crystal structure of SIRT2 used was taken from the human sirtuin C-pocket (PDB entry; 1J8F) (26). As the crystal structure of human SIRT1 has not been resolved yet, a homology model obtained through the hierarchical protein structure modeling approach based on secondary-structure enhanced Profile-Profile threading Alignment (PPA) and the iterative implementation of the Threading ASSEmbly Refinement (TASSER) program (27). The proteins were prepared in Discovery Studio 3.5, with the default parameters. The starting conformation was a low-energy conformer generated using modified CHARMm force field-based 3D structure minimization implemented in Discovery Studio's 'prepare ligands' protocol (28). Results of the docking studies suggested that toxoflavin would dock strongly into the binding site of the ribose and nicotinamide moieties of $\mathrm{NAD}^{+}$in SIRT1 and SIRT2. The strong interaction of toxoflavin with SIRT1 is attributed to the H-bonding interaction of both side chains of Asp348 and backbone - NH of Ile347 residues, as shown in Fig. 4. While the interaction of toxoflavin with SIRT2 forms a $\pi$-stacking interaction with Phe119, H-bonding interaction is not present. The binding energy of SIRT1- and SIRT2toxoflavin complexes were -181.20 and $-121.81 \mathrm{kcal} / \mathrm{mol}$, respectively, suggesting toxoflavin could bind to SIRT1 with an improved affinity compared with that of SIRT2.

\section{Discussion}

Sirtuins have received tremendous attention in the research fields of cancer, metabolic diseases, neurodegeneration and aging (2). Thus, small molecule sirtuin modulators of sirtuins have been explored targeting these diseases. SIRT1 activators are pursued for metabolic/neurodegenerative diseases and SIRT inhibitors are investigated in the oncology area. Controversy exists on the role of SIRT1 in tumorigenesis. Some evidence supports the role of SIRT1 as a tumor suppressor and some reports show that SIRT1 has an oncogenic function $(1,29)$. Thus, the identification of SIRT inhibitors will be important to elucidate the role of SIRT in tumorigenesis. Identified SIRT inhibitors can be useful tools for proving the concept of SIRT as a therapeutic target for cancer.

Toxoflavin was isolated 80 years ago from Pseudomonas (30) and its toxicity and antibiotic function are presumed to originate from inhibition of the respiratory chain (31). Toxoflavin derivatives were identified as actives in several high-throughput screening campaigns. Screening for Polo-like kinase 1, Akt and NIMA-related kinase 2 resulted in a series of compounds containing toxoflavin core structure (32-34). However, detailed characterization regarding the kinase inhibition was not performed. In this study, the screening of SIRT1 inhibitory activity identified toxoflavin as a potent in vitro SIRT1 modulator. EX-527 (also known as SEN0014196 and selisistat) is currently the strongest SIRT1 inhibitor in terms of in vitro activity (5). However, SIRT1-inhibitory activity is not observed in cell-based assay (data not shown). Toxoflavin has an in vitro activity similar to EX-527 and exhibits strong SIRT1 inhibition in cell-based assay (Fig. 2). Thus toxoflavin can be a better chemical probe than EX527 in the sirtuin research field.

In the inhibition of in vitro deacetylase activity, toxoflavin showed higher selectivity toward SIRT1 $\left(\mathrm{IC}_{50} 0.872 \mu \mathrm{M}\right)$ than SIRT2 $\left(\mathrm{IC}_{50} 14.4 \mu \mathrm{M}\right)$ (Fig. 1A). In western blotting for acetylated substrates of SIRT1 and SIRT2, however, toxoflavin exhibited similar activity toward both SIRT1 and SIRT2 (Fig. 2). The acetylated form of p53 and $\alpha$-tubulin were increased by toxoflavin from $1 \mu \mathrm{M}$ concentration. The inconsistency between the in vitro activity and cell-based activity may be due to the complex sirtuin biological system and remains to be elucidated.

Toxoflavin did not affect the acetylated level of p53 and $\alpha$-tubulin in MCF-7 cells, while levels in A549 cells were increased to a great degree (Fig. 2). The $\alpha$-tubulin acetylation level change toxoflavin was also examined in various other cell lines (data not shown). There are increases in SK-OV-3, DU-145, MKN-45 and U87MG cells. In addtion, in PANC-1 and MCF-7 cells, change in $\alpha$-tubulin acetylation level was not observed up to $10 \mu \mathrm{M}$ of toxoflavin treatment. There are various factors affecting these differences, such as SIRT2 expression level and basal $\alpha$-tubulin acetylation level in cell lines. It will be important to establish the mechanism of toxoflavin sensitivity in order to find biomarkers for SIRT inhibitors.

The preliminary study of structure-activity relationship for toxoflavin revealed that the triazine ring is critical to inhibitory potencies against SIRT1/2. Interestingly, substitution of the N-methyl group with $\mathrm{N}$-ethyl group and replacement of hydrogen in the triazine ring of toxoflavin with alkyl and aryl groups dramatically reduced SIRT2 inhibitory potency. Moreover, replacement of triazine with diazine abolished the inhibitory effect of toxoflavin derivatives against both SIRT1 and SIRT2.

SIRT1/2 are emerging as therapeutic targets for cancer and identification of SIRT1/2 inhibitors will expedite the development of an anticancer agent with a SIRT1/2 inhibitory mechanism. Here, toxoflavin is described as a potent and direct SIRT1/2 inhibitor with cytotoxic activity. Although clinical development of toxoflavin is limited by its toxicity, toxoflavin and its derivatives will serve as great chemical probes for SIRT1 and in the anticancer agent research area.

\section{Acknowledgements}

This study was supported by a grant of the NRF (2011-0010374) funded by the government of Korea (MEST), a grant from the Ministry of Trade, Industry and Energy (MOTIE), Korea Institute for Advancement of Technology (KIAT) through inter-ER cooperation projects (A004500005) and a grant (12182MFDS666) from Ministry of Food and Drug Safety.

\section{References}

1. Bosch-Presegue L and Vaquero A: The dual role of sirtuins in cancer. Genes Cancer 2: 648-662, 2011.

2. Carafa V, Nebbioso A and Altucci L: Sirtuins and disease: the road ahead. Front Pharmacol 3: 4, 2012. 
3. North BJ, Marshall BL, Borra MT, Denu JM and Verdin E: The human Sir2 ortholog, SIRT2, is an NAD ${ }^{+}$-dependent tubulin deacetylase. Mol Cell 11: 437-444, 2003.

4. Vaquero A, Scher MB, Lee DH, et al: SirT2 is a histone deacetylase with preference for histone H4 Lys 16 during mitosis. Genes Dev 20: 1256-1261, 2006.

5. Stunkel W and Campbell RM: Sirtuin 1 (SIRT1): the misunderstood HDAC. J Biomol Screen 16: 1153-1169, 2011.

6. Bonezzi K, Belotti D, North BJ, et al: Inhibition of SIRT2 potentiates the anti-motility activity of taxanes: implications for antineoplastic combination therapies. Neoplasia 14: 846-854, 2012.

7. Napper AD, Hixon J, McDonagh T, et al: Discovery of indoles as potent and selective inhibitors of the deacetylase SIRT1. J Med Chem 48: 8045-8054, 2005.

8. Bedalov A, Gatbonton T, Irvine WP, Gottschling DE and Simon JA: Identification of a small molecule inhibitor of Sir2p. Proc Natl Acad Sci USA 98: 15113-15118, 2001.

9. Mai A, Massa S, Lavu S, et al: Design, synthesis, and biological evaluation of sirtinol analogues as class III histone/protein deacetylase (Sirtuin) inhibitors. J Med Chem 48: 7789-7795, 2005.

10. Heltweg B, Gatbonton T, Schuler AD, et al: Antitumor activity of a small-molecule inhibitor of human silent information regulator 2 enzymes. Cancer Res 66: 4368-4377, 2006.

11. Outeiro TF, Kontopoulos E, Altmann SM, et al: Sirtuin 2 inhibitors rescue alpha-synuclein-mediated toxicity in models of Parkinson's disease. Science 317: 516-519, 2007.

12. Trapp J, Meier R, Hongwiset D, Kassack MU, Sippl W and Jung M: Structure-activity studies on suramin analogues as inhibitors of NAD ${ }^{+}$-dependent histone deacetylases (sirtuins). ChemMedChem 2: 1419-1431, 2007.

13. Lain S, Hollick JJ, Campbell J, et al: Discovery, in vivo activity, and mechanism of action of a small-molecule p53 activator. Cancer Cell 13: 454-463, 2008.

14. Lara E, Mai A, Calvanese V, et al: Salermide, a Sirtuin inhibitor with a strong cancer-specific proapoptotic effect. Oncogene 28 781-791, 2009.

15. Kalle AM, Mallika A, Badiger J, Alinakhi, Talukdar P and Sachchidanand: Inhibition of SIRT1 by a small molecule induces apoptosis in breast cancer cells. Biochem Biophys Res Commun 401: 13-19, 2010

16. Nebbioso A, Pereira R, Khanwalkar H, et al: Death receptor pathway activation and increase of ROS production by the triple epigenetic inhibitor UVI5008. Mol Cancer Ther 10: 2394-2404, 2011.

17. Zhang Q, Zeng SX, Zhang Y, et al: A small molecule Inauhzin inhibits SIRT1 activity and suppresses tumour growth through activation of p53. EMBO Mol Med 4: 298-312, 2012.

18. Machlowitz RA, Fisher WP, Betsey McKay S, Tytell AA and Charney J: Xanthothricin, a new antibiotic. Antibiot Chemother 4: 259-261, 1954
19. Black TH: An improved, large-scale synthesis of xanthothricin and reumycin. J Heterocyclic Chem 24: 1373-1375, 1987.

20. Spinks D, Shanks EJ, Cleghorn LA, et al: Investigation of trypanothione reductase as a drug target in Trypanosoma brucei. ChemMedChem 4: 2060-2069, 2009.

21. Todorovic N, Giacomelli A, Hassell JA, Frampton CS and Capretta A: Microwave-assisted synthesis of 3-arylpyrimido $[5,4$-e] $[1,2,4]$ triazine-5,7 $(1 \mathrm{H}, 6 \mathrm{H})$-dione libraries: derivatives of toxoflavin. Tetrahedron Lett 51: 6037-6040, 2010.

22. Peck B, Chen CY, Ho KK, et al: SIRT inhibitors induce cell death and p53 acetylation through targeting both SIRT1 and SIRT2. Mol Cancer Ther 9: 844-855, 2010.

23. Lu X, Magrane G, Yin C, Louis DN, Gray J and Van Dyke T: Selective inactivation of p53 facilitates mouse epithelial tumor progression without chromosomal instability. Mol Cell Biol 21: 6017-6030, 2001.

24. Vaziri H, Dessain SK, Ng Eaton E, et al: hSIR2(SIRT1) functions as an NAD-dependent p53 deacetylase. Cell 107: 149-159, 2001.

25. Venkatachalam CM, Jiang X, Oldfield $\mathrm{T}$ and Waldman $\mathrm{M}$ LigandFit: a novel method for the shape-directed rapid docking of ligands to protein active sites. J Mol Graph Model 21: 289-307, 2003.

26. Finnin MS, Donigian JR and Pavletich NP: Structure of the histone deacetylase SIRT2. Nat Struct Biol 8: 621-625, 2001.

27. Wu S, Skolnick J and Zhang Y: Ab initio modeling of small proteins by iterative TASSER simulations. BMC Biol 5: 17, 2007.

28. Brooks BR, Bruccoleri RE, Olafson BD, States DJ, Swaminathan S and Karplus M: CHARMM: A program for macromolecular energy, minimization, and dynamics calculations. J Comput Chem 4: 187-217, 1983.

29. Song S-H, Lee M-O, Lee J-S, Oh J-S, Cho S-U and Cha H-J: Sirt1 promotes DNA damage repair and cellular survival. Biomol Ther 19: 282-287, 2011.

30. van Veen AG and Mertens WK: Das Toxoflavin, der gelbe Giftstoff der Bongkrek. Rec Trav Chim 53: 398-404, 1934.

31. Latuasan HE and Berends W: On the origin of the toxicity of toxoflavin. Biochim Biophys Acta 52: 502-508, 1961.

32. Goh KC, Wang H, Yu N, et al: PLK1 as a potential drug target in cancer therapy. Drug Dev Res 62: 349-361, 2004.

33. Hayward DG, Newbatt Y, Pickard L, et al: Identification by high-throughput screening of viridin analogs as biochemical and cell-based inhibitors of the cell cycle-regulated nek2 kinase. J Biomol Screen 15: 918-927, 2010.

34. Burns S, Travers J, Collins I, et al: Identification of small-molecule inhibitors of protein kinase B (PKB/AKT) in an AlphaScreen ${ }^{\mathrm{TM}}$ high-throughput screen. J Biomol Screen 11: 822-827, 2006. 